\title{
IMPORTANCE OF FORENSICS OF MOBILE PHONES AS A TYPE OF DIGITAL FORENSICS IN THE PROCESS OF EVIDENCE
}

\section{Zivanka Miladinovic Bogavac}

Faculty of Business and Law of the "Union - Nikola Tesla" University, Belgrade, Serbia

\section{Djordje Spasojevic}

High School for Business Economics and Entrepreneurship, Belgrade, Serbia

OMESTE

JEL Category: L86, M15

\begin{abstract}
The fact is that mobile phones are increasingly replacing computers with features such as Internet access, emailing, access to social networks. With the advent of smartphones, the role of computers in information communication networks is reduced. Modern phones take on the role of participants in the cyberspace, both the potential victim and the object of protection, and the possible means of cyberattacks. With these facts, the field of evidence moves from tangible things into an intangible and hardto-prove field. Mobile phones become a source of data storage, which in addition to pointing to the commission of a criminal offense, performing and detecting communications and location of the phone users. With the help of them, we obtain a further complete picture of the planning and the place where the crime was committed. Since the data in the phone's memory is not completely erased with their dedicated removal, their obtaining is possible with the help of forensic tools specifically for this purpose. Digital Forensics that relates to computer forensics is necessary to complete with specialized forensic tools for smartphones. Therefore, the tendency is to apply and improve the forensics of mobile devices as a type of digital forensics and the development of forensic tools that will be specialized for these devices.
\end{abstract}

Keywords: digital forensics, forensic, mobile, cybercrime, cyberspace

\section{DETERMINATION \\ AND CLASSIFICATION OF DIGITAL FORENSICS}

Address of the corresponding author: Živanka Miladinović Bogavac 豐: zivankamiladinovic@gmail.com
To take the most out of digital evidence, forensic experts must understand and properly use 
scientific methods. Scientific methods together with digital forensic methods and techniques enable adaptability to various events and demands and ensure that conclusions are based on facts. Knowing the limits of forensic analysis of digital evidence will help the investigators to arrest criminals and release the innocent.

Computer or digital forensics denotes application of scientific methods with the aim of identification, gathering and analyzing data with preservation of the integrity of the original evidence and chain of jurisdiction with the aim of establishing potential digital evidence. Computer forensics can also be defined as the process of gathering, preservation, analysis, and presentation of digital evidence. Forensic tools enable recovery and analysis of deleted, hidden and temporary files which cannot be accessed in the usual way. A complete system for gathering, analyzing and making reports about the evidence acceptable to the court as well as recovery of the lost data.

During the 1980s, most of the digital forensic examination consisted of "live analyses", examination of digital media directly by using unspecialized tools. During the 90 s some free and other owner tools (hardware and software) were created to enable investigation without modifying media. This first set of tools was mainly focused on computer forensics (Casey, 2004).

Digital forensics is the application of methods of examination and techniques of analysis with the aim of finding computer evidence acceptable to the court. It is the application of computer science and mathematics for reliable and objective gathering, analysis, interpretation and presentation of digital evidence. It is the use of scientifically developed and tested methods of saving, gathering, validation, identification, analysis, interpretation, documenting and presentation of digital evidence obtained from digital sources for the need of reconstruction of the event characterized as a crime or as a help to predict unauthorized actions which threaten to interrupt planned operations.

Briefly, computer Forensics can also be defined as the process of collecting, preserving, analyzing and presenting digital evidence. Therefore, the goal of digital forensics is not only identifying, collecting and analyzing data but also preserving the integrity of original evidence to identify potential digital evidence. Digital forensics is based on the use and improvement of forensic tools. Forensic tools allow reimbursement and analysis of deleted, hidden and temporary files that cannot be accessed in the usual way. Digital tools are a method for collecting, analyzing, and producing evidence-based evidence and recovering lost data.

Based on the specificities of techniques, tools, and methods of examination in the forensic practice the following main areas in the field of digital forensics have been differentiated:

1. Computer forensics (acquisition and analysis of $\mathrm{HD}$ and other portable media)

2. Network forensics (intrusion into the network, abuse and so on)

3. Software forensics (examination of malware)

4. Active (live) forensics of systems (exposed host-servers, abuse of systems and so on).

\section{FORENSICS OF MOBILE DEVICES AS A TYPE OF DIGITAL FORENSICS}

As mobile technology progresses, the amount and type of data that can be found on the mobile device are constantly increasing. This fact is supported by the increasing use of mobile phones for storing and transferring personal and corporate information and using mobile phones in online transactions.

Mobile Forensics is a branch of digital forensics that relates to the recovery of digital evidence or data from a mobile device.

The term "mobile device" usually refers to mobile phones. However, this term should be comprehensively understood. By the term "mobile device" we can include any digital device with two characteristics:

1. internal memory

2. the ability to communicate.

So, under the term "mobile device" we can include PDAs, GPS devices, and tablets in addition to mobile phones.

The subject of mobile forensics can be:

- $\quad$ SMS received and sent (with date and time) 
- MMS messages received and sent (with date and time)

- Listing of incoming and outgoing calls (with date and time)

- Phonebook

- Photos, audio and video files

- Conversations from social applications (Viber, WhatsApp, Facebook Messenger, Skype)

- The location of the mobile phone at a certain time

- Records from calendars, notes, planner ...

- files of various formats (PDF, Excel, Word ...)

The unavailability of these data can occur for a number of reasons: random or deliberate deletion, factory reset of the phone, physical damage to the mobile phone, software errors, the result of a virus or malware program, and so on.

These data, potentially recoverable from a mobile phone, come from a variety of sources:

1. the memory of the phone,

2. SIM card and

3. memory cards such as SD cards.

In this regard, we can classify forensics that relates to mobile devices to the Forensics of internal and external memory. Under internal memory is a flash memory that consists of NAND or NOR types. External memory includes sim cards, SD cards (usually found in GPS devices as well as mobile phones), MMC cards, CF cards, and Memory Stick.

Although technically not part of the form of mobile devices, call details (and occasionally text messages) from providers often serve as "backup" evidence obtained after the mobile phone is confiscated. The European Union requires the Member States to retain certain telecommunications data for use in investigations.

\section{SHORT OVERVIEW OF THE FORENSICS PROCESS OF MOBILE DEVICES}

The first testing of mobile devices was used to analyze the contents of the phone directly over the screen and capture important content. However, it turned out to be a long-term process, and as the number of mobile devices began to grow, investigators were using more efficient means of data extraction. This process is one of the most demanding investigation procedures, due to rapid changes in the hardware and software structure and a large number of non-standard devices present on the market.

The whole process was facilitated by software or PDA software for synchronizing device data to a forensic computer for recording or sometimes simply performing computer forensics on the hard disk of a suspicious computer in which the data is synchronized. As well as that deleted data is obtained using a "flasher" or "twister" box, tools that were produced by OEMs to flash the phone's error correction or update.

The preparatory phase of the forensic process of mobile devices includes:

1. determining the network in which the phone works

2. identification of features and capabilities of the mobile device (manufacturer, model, serial number, wireless connectivity methods)

3. selection of the most suitable forensic treatment tool.

Mobile forensics tools are divided into two groups: GSM and CDMA types for acquisition.

In other words, some forensic tools only work on device analysis, while some devices and SIM cards work.

The most famous and commonly used, although not one tool for handling mobile devices and SIM cards are (Nolan, et al., 2005):

1. Paraben,

2. Logicube,

3. CellDEK kit,

4. Crownhill,

5. Inside Out Forensics and

6. Xygen software.

The choice of the type of forensic device to be used for mobile forensics is quite different from the standard forensic computer equipment, due to the variety of devices. When the most suitable forensic tool is selected, the isolation of the device is the next step. During the investigation of the mobile device, it must be isolated not only from 
other mobile phones but also from any communication using Bluetooth, Wi-Fi or infrared communication.

Isolation can be achieved by:

1. Faraday cage- prevents the communication of mobile devices with external wireless devices, prevents the receiving and sending of data and isolates the device.

2. Turning off the device and

3. By placing the device in a plane mode that excludes all wireless communication modes. (Volonino \& Anzaldua, 2008)

The next step after isolating the phone is that the battery is maintained, whilst avoiding the risk of losing data stored in the working memory (ROM).

This is followed by finding the required information. Regardless of whether these are GSM or CDMA devices, the data extraction procedures are slightly different. If it works through SIM cards, they are first cloned, or a data image is created using a card reader. Then make sure that any writing on the original medium is disabled. After extracting data for analysis, forensic tools perform "find and retrieve" automated software functions. (Nolan, et al., 2005)

\section{CONCLUSION}

As mobile technology progresses, the amount and type of data that can be found on the mobile device are constantly increasing. This fact is reinforced by the growing use of mobile phones for the storage and transfer of personal and corporate information, and the use of mobile phones in online transactions. On the one hand, the use of mobile phones has many benefits, and on the other hand in the last decade, there is also a numerous form of abuse of smartphones. Namely, mobile phones appear as a warehouse of information related to the commission of criminal offenses, whether it's about discovering or proving. These devices contain important information that will reveal the details of the commission of crimes. We can rightly expect that the evidence will be obtained by forensic analysis of mobile devices using effective forensic tools will replace classical evidence. Thereby achieving not only saving time and money, but also reducing the length of the evidence process and thus the burden of investigative and judicial authorities.

\section{WORKS CITED}

Casey, E. (2004). Digital Evidence and Computer Crime (2nd ed.). London: Elsevier Academic Press.

Nolan, R., Baker, M., Branson, J., Hammerstein, J., Rush, K., Waits, C., \& Schweinsberg, E. (2005). First responders Guide to Computer Forensics. Hanscom AFB, MA: CERT Training and Education.

Volonino, L., \& Anzaldua, R. (2008). Computer forensics for dummies. Hoboken:: Wiley Publishing, Inc.

Received for publication: 08.03 .2018

Revision received: $\quad 02.09 .2018$

Accepted for publication: 27.12 .2018

\section{How to cite this article?}

Style - APA Sixth Edition:

Miladinovic Bogavac, Z., \& Spasojevic, D. (2019, January 15). Importance of Forensics of Mobile Phones as a Type of Digital Forensics in the Process of Evidence. (Z. Čekerevac, Ed.) MEST Journal, 7(1), 48-52. doi:10.12709/mest.07.07.07 
Style - Chicago Sixteenth Edition:

Miladinovic Bogavac, Zivanka, and Djordje Spasojevic. 2019. "Importance of Forensics of Mobile Phones as a Type of Digital Forensics in the Process of Evidence." Edited by Zoran Čekerevac. MEST Journal (MESTE) 7 (1): 48-52. doi:10.12709/mest.07.07.07.

Style - GOST Name Sort:

Miladinovic Bogavac Zivanka and Spasojevic Djordje Importance of Forensics of Mobile Phones as a Type of Digital Forensics in the Process of Evidence [Journal] // MEST Journal / ed. Čekerevac Zoran. - Belgrade - Toronto: MESTE, January 15, 2019. - 1: Vol. 7. - pp. 48-52. doi:10.12709/mest.07.07.01.07

Style - Harvard Anglia:

Miladinovic Bogavac, Z. \& Spasojevic, D., 2019. Importance of Forensics of Mobile Phones as a Type of Digital Forensics in the Process of Evidence. MEST Journal, 15 January, 7(1), pp. 48-52.

Style - ISO 690 Numerical Reference:

Importance of Forensics of Mobile Phones as a Type of Digital Forensics in the Process of Evidence. Miladinovic Bogavac, Zivanka and Spasojevic, Djordje. [ed.] Zoran Čekerevac. 1, Belgrade Toronto : MESTE, January 15, 2019, MEST Journal, Vol. 7, pp. 48-52. 